\title{
MUNDO DO TRABALHO: \\ TRANSFORMAÇÕES E DESAFIOS NO PERÍODO RECENTE
}

\author{
Rosana Ribeiro
}

A obra $O$ sindicalismo equilibrista: entre o continuísmo e as novas práticas aborda as transformações e os desafios postos aos trabalhadores, aos sindicatos, às negociações coletivas, às diversas ações coletivas e à geração de emprego no período recente. Destarte, os autores nos convidam a fazer uma reflexão sobre temas importantes ao mundo do trabalho.

O livro contém quatro partes e 12 capítulos. A primeira parte, em três capítulos, refere-se ao sindicalismo, ao Estado e ao espaço público.

O capítulo 1 - "Trabalho, sociedade e os ciclos da esquerda brasileira", de Marcelo Ridenti - trata da história da esquerda brasileira, periodizada em ciclo anarquista, ciclo das vanguardas, ciclo das bases e ciclo da institucionalização defensiva. Segundo o autor, o ciclo da institucionalização defensiva seria caracterizado pela opção do "parâmetro institucional, de representação dentro da ordem para garantir e conquistar direitos, resistindo ao avanço neoliberal e à precarização do mundo do trabalho e da organização popular". Noutros termos, o autor aponta nesse ciclo o abandono da opção revolucionária e a adoção da opção institucional pela maioria dos partidos de esquerda no Brasil, como o Partido Comunista (PCdoB) e o Partido dos Trabalhadores (PT) - este estaria na iminência de tornar-se um partido social-liberal que adota medidas neoliberais na economia e políticas sociais compensatórias.

Entretanto, o autor admite que a opção pela institucionalidade subordinada do PT pode sofrer abalos, pois a esquerda vai se recompor. No dizer de Ridenti (2006, p. 40), é "[...] difícil imaginar que a ordem social e econômica hoje dominante possa ser aceita sem contestação, especialmente numa sociedade tão desigual como a brasileira". Essa afirmação, porém, suscita questionamentos; por exemplo, de onde surgiria essa reorientação da esquerda brasileira? Afinal, segundo esse autor, grande parte dos partidos de esquerda está comprometida com a opção da institucionalização defensiva. Além disso, nessa reorientação, retomaríamos o projeto revolucionário ou teríamos uma nova vertente da via institucional?

O capítulo 2 - "Do confronto à negociação: a CUT na passagem dos anos 1990 ou equívoco teórico", de Marco Ferraz - analisa as alterações das estratégias do sindicalismo-CUT (Central Única dos Trabalhadores). Para Ferraz, as estratégias adotadas resultam não só dos limites estabelecidos pelos contornos mais gerais da realidade objetiva, mas também das opções individuais desses dirigentes. No início dos anos 1990, os dirigentes do sindicalismo-CUT depararam-se com duas possíveis escolhas: ou insistiam na opção do confronto aberto ou adotavam uma via propositiva; optaram pela estratégia que incluía a via propositiva. No entanto, segundo Ferraz, podemos entender os determinantes da adoção dessa opção à medida que analisamos o papel da CUT na transição democrática. Para esse autor, o sindicalismo-CUT constituiu um dos principais artífices da democratização no Brasil. Esse papel assumido pelo sindicalismo-CUT já sinalizava que seus dirigentes pretendiam fazer uso das oportunidades oferecidas pela democracia, portanto participar era inevitável. Nesse contexto democrático construído com a ajuda do sindicalismo-CUT: "Confronto e negociação tornam-se dois lados de uma mesma moeda, predominando um ou outro em função de opções táticas frente às dificuldades objetivas, tanto estruturais como conjunturais" (FERRAZ, 2006, p. 70). Ferraz aponta, então, que a oposição entre negociação e confronto se revela inadequada e incapaz de apreender a mesclagem que envolve os processos de conflito e negociação. Desde os anos 1990, há espaço no Brasil para o enfrentamento e a resolução dos conflitos, por isso uma opção pela tática de confronto precedendo a negociação poderia significar isolamento político. Ademais, a opção propositiva do sindicalismo-CUT não elimina a possibilidade de emergência de ações contra-hegemônicas como a luta pelo Contrato Nacional Metalúrgico. Contudo, essas 
negociações coletivas conduzidas pelos dirigentes do sindicalismo-CUT nos levam a questionar se conseguiram manter e sustentar direitos adquiridos pelos trabalhadores e, de forma sintética, questionar o resultado da barganha coletiva conduzida por esses dirigentes.

O capítulo 3 - "Novo sindicalismo, pensamento social brasileiro e intelectuais", de Marco Antonio Perruso - contém uma reflexão sobre o significado do termo "novo sindicalismo" em diversos autores em contraponto ao termo "velho sindicalismo". Em resumo, o novo sindicalismo seria combativo, reivindicativo, anticorporativo, autônomo, capaz de integrar pautas econômicas, sociais e políticas, organizado massiva e democraticamente pela base, antivanguardista, fomentador de comissões ou delegações por local de trabalho e, por fim, criador de um novo sujeito coletivo de feição operária na sociedade brasileira. Mas essas características permanecem nos sindicatos vinculados ao novo sindicalismo?

A segunda parte é dedicada à temática categorias profissionais e desafios do coletivo, reunindo quatro capítulos.

No capítulo 4 - “Ação política na fábrica contemporânea”, de Elaine Marlova Venzon Francisco -, a autora faz um excelente estudo sobre as particularidades da ação política em uma planta produtiva criada com base nas novas formas de organização da produção e do trabalho, qual seja, o consórcio modular em Resende (Rio de Janeiro). Sua pesquisa nos permite apreender a ação política da comissão de fábrica e do sindicato na empresa - no caso da comissão, ela desenvolveu algumas táticas em suas ações, como o fator-surpresa e a ameaça ao comprometimento da produtividade. A relação entre sindicato dos trabalhadores e comissão se transformou, ao longo do tempo, de conflituosa para cooperada. Além disso, as ações da comissão de fábrica não se dirigem exclusivamente a seus representados legais (funcionários da empresa contratante, a Volkswagen), pois essa comissão também influencia positivamente, mas de forma indireta, as condições de trabalho dos empregados das firmas contratadas. O chão-de-fábrica segue, portanto, marcado por conflitos e ações de resistência, bem como por momentos de negociação. Embora as novas formas de organização da produção e do trabalho dificultem o surgimento de ações políticas comprometidas com os interesses dos trabalhadores, ainda é possível criar e recriar espaços de resistência.

O capítulo 5 - "Modernização portuária: as transformações do trabalho e das instituições sindicais no Porto de Santos", de Carla Regina Mota Alonso Diéguez - compreende uma análise dos impactos da reestruturação portuária sobre o sindicato dos trabalhadores. Esse sindicato se caracterizava pela existência do closed shop, mas a modernização portuária fez o controle das escalas de trabalho ser repassado ao órgão gestor de mão-de-obra. Essas transformações alteraram radicalmente a ligação entre sindicato e trabalhador, pois promoveram um esvaziamento na vida sindical. Embora Diéguez afirme que a crise de representatividade desse sindicato resulte de mudanças promovidas pela modernização portuária, seus dirigentes sindicais orientaram suas ações com base no papel de agente de intermediação de mão-de-obra assumido pelo sindicato. Assim, não seria o caso de se pensar que as opções norteadoras das ações desses sindicalistas contribuíram decisivamente para a crise desse sindicato?

O capítulo 6 - "O sindicalismo diante das transformações no mundo do trabalho: o setor de telecomunicações do Paraná pós-privatização", de Ivana Lima de Almeida - corresponde a um importante estudo do impacto da privatização no Sindicato dos Trabalhadores em Empresas de Telecomunicações do Paraná (Sinttel-PR). A autora verifica que as negociações coletivas entabuladas entre 1998 e 2002 - portanto, após a privatização do setor de telecomunicações - foram marcadas por perda de direitos e pela tentativa de reconquistar antigos direitos. Almeida relata que houve mudanças na diretoria do Sinttel em 1999; a partir de então, os dirigentes sindicais eleitos passaram a defender uma estratégia propositiva, enquanto os antigos diretores defendiam uma estratégia conflitiva. Além disso, os novos sindicalistas advogavam o sistema atual de sindicato único por categoria e a manutenção da contribuição sindical. Essa autora sugere que o processo de privatização do setor, que se conjugou com a atuação desses dirigentes, explicaria a perda de direitos dos trabalhadores nas negociações coletivas no período referido. No entanto, no ano de 1999, quais foram os principais determinantes da derrota dos sindicalistas que se baseavam em uma estratégia de confronto? Essa estratégia conseguiria reverter os resultados das negociações coletivas? $\mathrm{O}$ termo estratégia propositiva não omite a diversidade de ações e reações nos sindicatos enquadrados nessa estratégia?

No capítulo 7 - "A história do sindicalismo ferroviário paulista (1930-1961)", de Marco Henrique Zambello -, o autor analisa os feitos desse sindicato. O resgate das vitórias e derrotas desses sindicalistas revela a importância da luta dos ferroviários paulistas no passado recente. Todavia, a partir dos anos 1990, as 
condições objetivas dificultaram significativamente a atividade sindical. Esse segmento da atividade econômica, bem como outros, vivenciariam transformações tais como a privatização, a adoção de novos métodos de gerenciamentos, a redução do número de funcionários etc. No caso das ferrovias bandeirantes, na década de 1960, o número de trabalhadores perfazia 20 mil, mas, no presente, esse número não ultrapassa 1100 funcionários. Ou seja, os ferroviários transformaram-se em uma categoria em extinção. Certamente, a realidade objetiva gera desafios e limitações ao exercício da atividade sindical, no entanto as respostas e as estratégias que cada sindicato adota diante das crises e dificuldades também influenciam sua capacidade de se transmutar e sobreviver aos novos tempos.

Por sua vez, a terceira parte, composta de três capítulos, compreende várias reflexões sobre mudanças no trabalho e ressignificações.

O capítulo 8 - "Juventude e sociabilidade: o novo perfil do operário da Mercedes Benz/ABC", de Renan Araújo - contém uma análise do jovem operário da planta da Mercedes Benz (MMB) no ABC paulista. O cotidiano desse jovem é marcado pela pressão na fábrica - elevar a produtividade - e na vida familiar - ter um futuro bem-sucedido; além disso, a busca da empregabilidade também o pressiona. Dito de outro modo, a manutenção do emprego e a saída do desemprego são uma responsabilidade individual. $\mathrm{O}$ agir isoladamente, portanto, influencia a identidade da juventude. Nesse contexto, os jovens estariam mais propensos a práticas individualistas em vez de práticas coletivas. Distinto do perfil do velho operário que ainda permanece na fábrica, esse perfil questiona as práticas juvenis. Araújo aponta ainda que as mudanças na práxis do Sindicato dos Metalúrgicos do $\mathrm{ABC}$, como a alteração de um padrão de atuação conflitivo para um padrão propositivo, contribuíram para formar a nova identidade do jovem operário.

Entretanto, esses jovens ainda aderem às ações e mobilizações propostas por esse sindicato; também cabe ressaltar que o arrefecimento nas greves e manifestações sindicais no passado recente tem motivações complexas e que a mudança no perfil do jovem operário é apenas um dos elementos que dificultam a ação sindical. Nesses termos, podemos perguntar, se acaso esse sindicato pautasse suas ações em uma lógica meramente de confronto, qual seria o efeito final sobre a adesão dos jovens operários marcados por um perfil individualista: maior afastamento ou maior aproximação?

O capítulo 9 - "O mito da qualificação como requisito para a superação do desemprego. A odisséia da exclusão dos jovens no Brasil", de André Langer - faz uma reflexão sobre os determinantes das difículdades de inserção dos jovens no mercado de trabalho no Brasil. Vários estudiosos apontam como grande dificuldade de inserção dos jovens a baixa qualificação, entendida como nível de escolaridade. Embora os jovens adultos tenham a maior proporção de pessoas com 11 anos ou mais de estudo, eles têm a segunda maior taxa de desocupação. Como ressalta Langer, um determinante crucial dessas elevadas taxas, inclusive no caso dos jovens, é o desempenho macroeconômico medíocre das últimas décadas.

O capítulo 10 - "Emprego industrial no Brasil nos anos 90, o que mudou?”, de Darcilene Cláudio Gomes analisa detalhadamente as mudanças na economia brasileira, o encolhimento do emprego industrial entre 1992 e 2001 e seus impactos. Gomes ressalta que os setores intensivos em trabalho tiveram maior variação relativa em seu produto. $\mathrm{O}$ resultado desse ajuste no mercado de trabalho foi uma redução no emprego em vários ramos, como a indústria do fumo e a de fibras. Além disso, o rendimento médio dos trabalhadores teve queda no período anterior. A autora, portanto, desvenda um cenário desfavorável ao trabalhador industrial. 2000

A parte quatro, com dois capítulos, é dedicada ao tema do sindicalismo em transformação a partir do ano

O capítulo 11 - "As várias manifestações de crise no sindicalismo e a crítica ao pensamento generalizante de crise", de Maria Aparecida Bridi - contém uma reflexão instigante sobre os significados da atual crise do sindicalismo. Vários estudiosos apontaram que essa crise conduziria ao fim do trabalho e do sindicato. Contudo, Bridi aponta que crise é um momento de transição, de transformação e de tomada de decisões. Em particular no Brasil, a crise sindical impôs uma reorientação na elaboração das estratégias, pois alguns sindicatos ampliaram seu raio de atuação para além dos muros da fábrica, enquanto outros se transformaram em empresasclube, além de assumirem um caráter assistencialista. A pesquisa no Sindicato dos Metalúrgicos da Grande Curitiba (SMC), realizada por essa autora, revelou uma alteração em suas estratégias. Bridi constatou que esse sindicato abandonou sua postura assistencialista no sentido tradicional e adotou uma postura mais comprometida com os interesses de seus representados. A autora conclui que as condições adversas do cenário atual 
não estabelecem necessariamente o fim do movimento sindical, mas exigem uma reorientação de suas estratégias. Em meio a essa luta, alguns sindicatos conseguem brechas e espaços de reorganização. As generalizações acerca dos impactos da atual crise sindical, portanto, são inapropriadas.

O capítulo 12 - "CUT e reforma sindical: a noção de sindicalismo produzida no Fórum Nacional do Trabalho", de Sidartha Sória-Silva - compreende um exaustivo estudo das teses oficiais dos congressos da CUT e da posição dessa central no Fórum Nacional do Trabalho. Sória-Silva identifica o surgimento das propostas oficiais acerca do sindicalismo propositivo nesses documentos, os quais contêm mudanças que nos ajudam a compreender as propostas e a postura dos dirigentes cutistas nesse fórum. Todavia, se as teses oficiais refletem uma posição majoritária no congresso da CUT, os congressos são marcados pela presença de grupos com posições divergentes. Assim, cabe perguntar se os defensores dos documentos oficiais conseguiram amplo apoio, se as teses foram aprovadas em decisões apertadas e se as mudanças nas teses oficiais da CUT não expressariam uma alteração na correlação de forças no interior dessa central.

Rosana Ribeiro (rosanaribeiro@netsite.com.br) é Professora Doutora do Instituto de Economia da Universidade Federal de Uberlândia (UFU).

\section{REFERÊNCIASBIBLIOGRÁFICAS}

ALMEIDA, I. L. 2006. O sindicalismo diante das transformações no mundo do trabalho : o setor de telecomunicações do Paraná pós-privatização. In : ARAÚJO, S. M.; BRIDI, M. A. \& FERRAZ, M. (orgs.). $O$ sindicalismo equilibrista : entre o continuísmo e as novas práticas. Curitiba : UFPR.

ARAÚJO, R. 2006. Juventude e sociabilidade : o novo perfil do operário da Mercedes Benz/ABC. In : ARAÚJO, S. M.; BRIDI, M. A. \& FERRAZ, M. (orgs.). O sindicalismo equilibrista: entre o continuísmo e as novas práticas. Curitiba: UFPR.

ARAÚJO, S. M.; BRIDI, M. A. \& FERRAZ, M. (orgs.). 2006. O sindicalismo equilibrista : entre o continuísmo e as novas práticas. Curitiba : UFPR.

BRIDI, M. A. 2006. As várias manifestações de crise no sindicalismo e a crítica ao pensamento generalizante de crise. In : ARAÚJO, S. M.; BRIDI, M. A. \& FERRAZ, M. (orgs.). O sindicalismo equilibrista : entre o continuísmo e as novas práticas. Curitiba : UFPR.

DIÉGUEZ, C. R. M. A. 2006. Modernização portuária : as transformações do trabalho e das instituições sindicais no Porto de Santos. In : ARAÚJO, S. M.; BRIDI, M. A. \& FERRAZ, M. (orgs.). O sindicalismo equilibrista : entre o continuísmo e as novas práticas. Curitiba : UFPR.

FERRAZ, M. 2006. Do confronto à negociação : a CUT na passagem dos anos 1990 ou equívoco teórico. In : ARAÚJO, S. M.; BRIDI, M. A. \& FERRAZ, M. (orgs.). O sindicalismo equilibrista : entre o continuísmo e as novas práticas. Curitiba: UFPR.

FRANCISCO, E. M. V. 2006. Ação política na fábrica contemporânea. In : ARAÚJO, S. M.; BRIDI, M. A. \& FERRAZ, M. (orgs.). O sindicalismo equilibrista : entre o continuísmo e as novas práticas. Curitiba : UFPR.

GOMES, D. C. 2006. Emprego industrial no Brasil nos anos 90, o que mudou? In : ARAÚJO, S. M.; BRIDI, M. A. \& FERRAZ, M. (orgs.). O sindicalismo equilibrista : entre o continuísmo e as novas práticas. Curitiba : UFPR.

LANGER, A. 2006. O mito da qualificação como requisito para a superação do desemprego. A odisséia da exclusão dos jovens no Brasil. In : ARAÚJO, S. M.; BRIDI, M. A. \& FERRAZ, M. (orgs.). O sindicalismo equilibrista : entre o continuísmo e as novas práticas. Curitiba : UFPR.

PERRUSO, M. A. 2006. Novo sindicalismo, pensamento social brasileiro e intelectuais. In : ARAÚJO, S. M. BRIDI, M. A. \& FERRAZ, M. (orgs.). O sindicalismo equilibrista : entre o continuísmo e as novas práticas. Curitiba : UFPR. 
RIDENTI, M. 2006. Trabalho, sociedade e os ciclos da esquerda brasileira. In : ARAÚJO, S. M.; BRIDI, M. A. \& FERRAZ, M. (orgs.). O sindicalismo equilibrista : entre o continuísmo e as novas práticas. Curitiba : UFPR.

SÓRIA-SILVA, S. 2006. CUT e reforma sindical : a noção de sindicalismo produzida no Fórum Nacional do Trabalho. In : ARAÚJO, S. M.; BRIDI, M. A. \& FERRAZ, M. (orgs.). O sindicalismo equilibrista : entre o continuísmo e as novas práticas. Curitiba : UFPR.

ZAMBELLO, M. H. 2006. A história do sindicalismo ferroviário paulista (1930-1961). In : ARAÚJO, S. M.; BRIDI, M. A. \& FERRAZ, M. (orgs.). O sindicalismo equilibrista : entre o continuísmo e as novas práticas. Curitiba:UFPR. 